\title{
Gamification in sport apps: the determinants of users' motivation
}

\author{
Paula Bitrián, Isabel Buil and Sara Catalán \\ Department of Marketing Management, University of Zaragoza, Zaragoza, Spain
}

\begin{abstract}
Purpose-Gamification is a tool with great potential to motivate individuals to increase their physical activity. That is why sport apps for mobile devices, such as Nike+ or Strava, have integrated game elements. There is, however, little evidence of gamification's effectiveness in this field. Therefore, the aim of the present study is to analyze the impact of game elements included in gamified sports' apps on the satisfaction of basic psychological needs (i.e. competence, autonomy and relatedness). Similarly, the research analyzes the impact of these needs on autonomous motivation.

Design/methodology/approach - To achieve these goals, data were collected from users of gamified sport apps, using an online questionnaire. The data were analyzed using partial least squares structural equation modeling.

Findings - The results showed that interaction in the app with achievement-related game elements satisfied the needs for competence, autonomy and relatedness; social-related elements satisfied the need for relatedness; and immersion-related elements satisfied the needs for competence and autonomy. Similarly, satisfaction of the needs for autonomy and relatedness while using the app is crucial to experience autonomous motivation.

Practical implications - The findings of this study provide guidelines for practitioners and app developers. Originality/value - Based on self-determination theory, the paper provides new insights into the relationship between game elements included in sport apps and individuals' basic psychological needs and motivation.
\end{abstract}

Keywords Gamification, Sport apps, Game elements, Self-determination theory, Motivation

Paper type Research paper

\section{Introduction}

Over the last few years, many organizations have shown increased interest in using game elements to motivate people to behave in certain ways (Koivisto and Hamari, 2019a). The success of this practice, known as "gamification," has received great attention from both academics and professionals (Hamari and Parvinen, 2018).

The underlying concept of gamification is the application of game design elements (e.g. points, rules, challenges, rewards, competition) in non-game contexts (Deterding et al., 2011; Seaborn and Fels, 2015) to harness the motivational and attractive power of games to allow people to achieve higher levels of motivation. This trend has been observed in a variety of fields, such as tourism (Sigala, 2015), education (Connolly et al., 2012), marketing (Lucassen and Jansen, 2014) and finance (Baptista and Oliveira, 2017). Koivisto and Hamari (2019a) also pointed out that gamification is particularly beneficial in contexts where individuals need to display long-term commitment and persistence in behaviors, and in contexts generally associated with procrastination. Hence, an area which has received special attention from

(C) Paula Bitrián, Isabel Buil and Sara Catalán. Published in European Journal of Management and Business Economics. Published by Emerald Publishing Limited. This article is published under the Creative Commons Attribution (CC BY 4.0) licence. Anyone may reproduce, distribute, translate and create derivative works of this article (for both commercial and non-commercial purposes), subject to full attribution to the original publication and authors. The full terms of this licence may be seen at: http://creativecommons.org/licences/by/4.0/legalcode

This study was supported by the Government of Spain and the European Regional Development Fund (project ECO2017-82103-P) and by the Government of Aragon (pre-doctoral grant BOA 15/11/ 2019 and GENERES Group S-54_17R) co-financed by FEDER 2014-2020 'Building Europe from Aragon'.

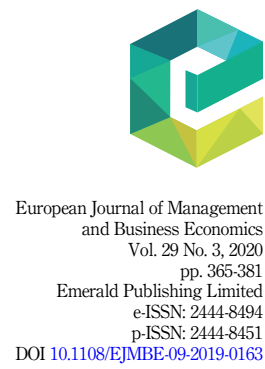

Received 20 September 2019 Revised 29 January 2020 Accepted 29 March 2020 
EJMBE 29,3 both academics (Matallaoui et al., 2017) and professionals (Koivisto and Hamari, 2019b)is health and sports.

Gamification has been postulated as an effective tool for motivating people to increase their physical activity (Chen and $\mathrm{Pu}, 2014$ ) and improve their mood (Huang et al., 2017). In this sense, there has been a remarkable increase in gamified sport apps, such as Nike+, Strava, Fitbit and Endomondo (Edwards et al., 2016), in parallel with the growth of gaming apps in mobile devices. Applying the principles of gamification, these apps include various game elements (e.g. challenges, medals, rankings, competitions, avatars) to encourage and maintain behavioral habits associated with physical exercise. In this way, they influence people to perceive exercise as an interesting, enjoyable and fun activity, and thereby increase their motivation.

Although there is a growing literature on gamification, there are important shortcomings of previous research with regard to theoretical, empirical and methodological issues. First, despite the suitability of motivational frameworks, such as self-determination theory (Ryan and Deci, 2000), to understand gamification effects, previous studies have noticed that there is a lack of theoretical foundation to explain the motivational effects of gamification and that few studies are based on theoretical frameworks (Hamari et al., 2014; Seaborn and Fels, 2015; Johnson et al., 2016; Matallaoui et al., 2017; Sailer et al., 2017). Second, evidence about the effectiveness of gamification in the context of health and well-being is also scarce (Edwards et al., 2016; Johnson et al., 2016; Sardi et al., 2017; Koivisto and Hamari, 2019b). Third, recent literature reviews have revealed a lack of knowledge about the effects of the different game elements, as most studies have focused on analyzing gamification as a uniform concept (Johnson et al., 2016; Sailer et al., 2017). Another problem in previous studies is that many of them have focused on analyzing users' behaviors (Johnson et al., 2016; Hamari, 2017) and have not considered psychological variables (Seaborn and Fels, 2015), such as motivation. Finally, many of the studies on gamification have been criticized for their lack of validated instruments (Matallaoui et al., 2017).

To address these gaps, this research seeks to better understand how gamification increases individuals' motivation. Specifically, based on self-determination theory, this study empirically analyzes the impact of various game elements included in sport apps on the satisfaction of the three basic psychological needs of competence, autonomy and relatedness, and their influence on autonomous motivation.

This study contributes to the literature in various ways. First of all, it fills an existing gap in the current academic literature on gamification. Drawing on self-determination theory, one of the most influential theories of human motivation, it responds to calls for more research examining gamification effects on users' motivation in the specific context of gamified sport apps. In addition, it extends previous gamification research by empirically analyzing how different game elements influence individuals' basic psychological needs and motivation. Finally, the study has practical implications for gamified apps designers as it offers useful advice on how to design gamified applications.

\section{Self-determination theory}

At the core of gamification is the use of the motivational power of games to promote and drive certain individual behaviors (Robson et al., 2015). Taking this into account, to create effective gamified experiences, it is very important to understand individuals' motivational processes.

One of the most commonly used theories to analyze human motivation is selfdetermination theory (Deci, 1975), which initially distinguished two types of motivation: intrinsic and extrinsic. People who display intrinsically motivated behaviors are actively engaged with their tasks, find them interesting and do not seek other results beyond fun (Ryan and Deci, 2000). However, many activities are not perceived as interesting by humans, 
and, therefore, their motivation has to be acquired extrinsically, through a kind of external regulation (Deci and Ryan, 2015). Self-determination proposes that extrinsically motivated behaviors can vary in the degree to which they are controlled as opposed to autonomous (Deci Gamification in sport apps et al., 1996), resulting in four sub-categories of extrinsic motivation: external regulation, introjected regulation, identified regulation and integrated regulation. First, external regulation is presented as the least autonomous (i.e. most controlled) form of extrinsic motivation, since individuals' behavior is externally controlled by others; that is, they act to achieve tangible rewards or avoid punishments determined by others (Deci and Ryan, 2000). The next level is introjected regulation, which refers to behaviors motivated by internal pressures (Deci and Ryan, 2000). This type of motivation is related to the ego, as people act to demonstrate their ability or to avoid guilt and shame (Ryan and Deci, 2000). The following level of extrinsic motivation is identified regulation, which corresponds to behaviors that occur when individuals identify themselves with the value of their behaviors and do not act only because they think they are supposed so to do (Deci and Ryan, 2000). Finally, integrated regulation is the most autonomous (or self-determined) form of extrinsic motivation, as the individual assimilates external regulations and acts with total willingness (Deci et al., 1996).

With this subdivision of extrinsic motivation, the initial differentiation within selfdetermination theory (i.e. intrinsic vs extrinsic motivation) shifted to a focus on autonomous versus controlled motivation. Autonomous motivation "involves behaving with a full sense of volition and choice" (Deci and Ryan, 2008, p. 14) and is comprised of identified and integrated forms of extrinsic motivation and intrinsic motivation. On the other hand, controlled motivation "involves behaving with the experience of pressure and demand toward specific outcomes that comes from forces perceived to be external to the self" (Deci and Ryan, 2008, p. 14). External and introjected forms of extrinsic motivation are considered forms of controlled motivation. Finally, self-determination theory also posits amotivation as the lack of motivation to carry out target behavior (Deci and Ryan, 2000).

Depending on the type of motivation that individuals possess, they tend to behave in different ways. Specifically, people who are motivated autonomously behave voluntarily because they consider their tasks as interesting and enjoy them. On the other hand, people with controlled motivation behave through obligation, which leads them to experience pressure (Deci and Ryan, 2015). Therefore, to achieve the best outcomes from any form of activity, it is preferable that individuals are autonomously motivated.

Taking the importance of autonomous motivation into account, self-determination theory has analyzed the factors that facilitate it. Specifically, cognitive evaluation theory (Ryan and Deci, 2000), a sub-theory of self-determination theory, proposes that satisfaction of individuals' basic psychological needs fosters greater autonomous motivation. According to this theory, in addition to basic physiological needs, such as eating, drinking and sleeping, humans have three basic psychological needs that they wish to meet: competence, autonomy and relatedness (Deci and Ryan, 2000). Competence is the individual's sense of ability to understand and develop an activity satisfactorily (White, 1959); autonomy is related to the capacity of choice (de Charms, 1968); relatedness is the feeling of belonging and connection with others (Baumeister and Leary, 1995).

Self-determination theory has been used to explain the motivation of individuals in a variety of contexts, such as education (van Roy and Zaman, 2019), work (de Cooman et al., 2013) and health (Ng et al., 2012). In addition, it has been applied in the context of games to investigate players' motivation and the factors that influence it (Ryan et al., 2006). Specifically, it has been shown that games foster a sense of competition through challenges, feedback and rewards. In addition, they provide autonomy through strategic flexibility and the possibility of making choices about tasks and objectives. Finally, they support relatedness by allowing interactions between the players (Ryan et al., 2006). 
EJMBE 29,3

368

\section{Research model and proposed hypotheses}

According to Koivisto and Hamari (2019a), game elements can be classified into three groups: (1) achievement-related elements, (2) social-related elements and (3) player immersion-related elements.

The most often used game elements in gamification are achievement related. These include badges, points, leaderboards, virtual currencies, progress bars and different difficulty levels (Koivisto and Hamari, 2019a). Previous studies have analyzed the effects of these types of game elements on individuals. Ding et al. (2018) found that systems that contained badges, leaderboards and progress bars facilitated user engagement. Similarly, Hassan et al. (2019) found that leaderboards, medals and levels provide individuals with a feedback system on their performance, which leads to greater intention to continue using a specific gamified system. In addition, although some studies have considered achievement-related game elements as extrinsic motivational aspects that have no effect on basic psychological needs (Mekler et al., 2017), most studies find that these gamification elements are positively associated with the satisfaction of the three basic psychological needs of competence, autonomy and relatedness (Xi and Hamari, 2019). For example, badges (Peng et al., 2012; Sailer et al., 2013, 2017; van Roy and Zaman, 2019) and leaderboards (Sailer et al., 2013, 2017) provide positive feedback on individuals' performances by showing their achievements, which creates a feeling of competition. Similarly, van Roy and Zaman (2019) found that setting weekly challenges of gradually increasing difficulty in an educational environment provided a greater sense of competence, autonomy and relatedness. Sailer et al. (2017) showed that badges, leaderboards and graphics met the satisfaction of the need for autonomy by increasing the sense of task and creating meaning at game level. Finally, Sailer et al. (2013) established that leaderboards, which provide a team-level score, also facilitated team members' feelings of relatedness.

Social-related game elements include competition with others, teams, cooperation and social networking features (Koivisto and Hamari, 2019a). Previous studies have found a positive influence of teammates' relationships on their intention to do their best (Peng et al., 2012), and competition with other teams has been found to facilitate a sense of belonging (van Roy and Zaman, 2019). These elements are also related to the satisfaction of the three basic psychological needs. For example, van Roy and Zaman (2019) confirmed that group competition had a positive impact on the promotion of the psychological needs of competence, autonomy and relatedness. On the other hand, Sailer et al. (2017) found that participants in a game involving teammates experienced higher levels of social relatedness. However, they did not prove this positive effect in the case of the need for autonomy. Finally, $\mathrm{Xi}$ and Hamari (2019) demonstrated that cooperation, competition and connection with social networking features facilitated the satisfaction of the needs for competence, autonomy and relatedness.

Finally, immersion-related elements mainly include avatars, narratives, stories and customization (Koivisto and Hamari, 2019a). Bormann and Greitemeyer (2015) found that narrative is positively associated with the satisfaction of the needs for competence, autonomy and relatedness. In the context of gamification in sport, Peng et al. (2012) showed that other immersion-related features, such as the possibility of customizing characters, positively influenced the satisfaction of the need for autonomy. Similarly, Kim et al. (2015) found that customization had a positive effect on autonomy. Sailer et al. (2013) also proposed that using stories and avatars facilitated a sense of autonomy. Finally, Sailer et al. (2017) confirmed there was a positive relationship between the use of avatars and stories and the satisfaction of the need for relatedness, whereas Xi and Hamari's (2019) study into online brand communities proved that avatars, narratives and customization had a positive influence on the satisfaction of the need for autonomy.

Taking these arguments into account, the following hypotheses are proposed: 
H1. Achievement-related app elements facilitate the satisfaction of the needs for (a) Gamification in competence, (b) autonomy and (c) relatedness.

H2. Social-related app elements facilitate the satisfaction of the needs for (a) competence, (b) autonomy and (c) relatedness.

H3. Immersion-related app elements facilitate the satisfaction of the needs for (a) competence, (b) autonomy and (c) relatedness.

Self-determination theory posits that contexts that satisfy the basic psychological needs for competence, autonomy and relatedness facilitate autonomous motivation (Deci and Ryan, 2000), which, in turn, leads to more favorable psychological results and greater well-being (Ryan and Deci, 2000). This relationship has been proven in multiple contexts. In the specific area of games, Ryan et al. (2006) stated that games which allow players to feel competent, provide autonomy and facilitate relationships with other players promote greater intrinsic motivation. In the context of sports and health, $\mathrm{Ng}$ et al. (2012) also found a positive relationship between the satisfaction of psychological needs and autonomous motivation, which resulted in beneficial health outcomes. Similarly, Peng et al. (2012), in an analysis of exercise games, found that game characteristics which support competition and autonomy enhance players' enjoyment, their motivation to continue playing, and increase their intention to recommend the game. Finally, other authors, such as Edmunds et al. (2007), have found that satisfaction of the three basic psychological needs is associated with higher levels of exercise, motivation and well-being. Taking these arguments into account, we propose the following hypotheses:

H4a. The satisfaction of the need for competence has a positive impact on autonomous motivation.

H4b. The satisfaction of the need for autonomy has a positive impact on autonomous motivation.

H4c. The satisfaction of the need for relatedness has a positive impact on autonomous motivation.

Figure 1 shows the proposed model.

\section{Methodology}

\subsection{Procedure}

To test the hypotheses, a market study with users of gamified sport apps was conducted.

Data collection took place between May and June 2019. Due to the difficulty to get access to

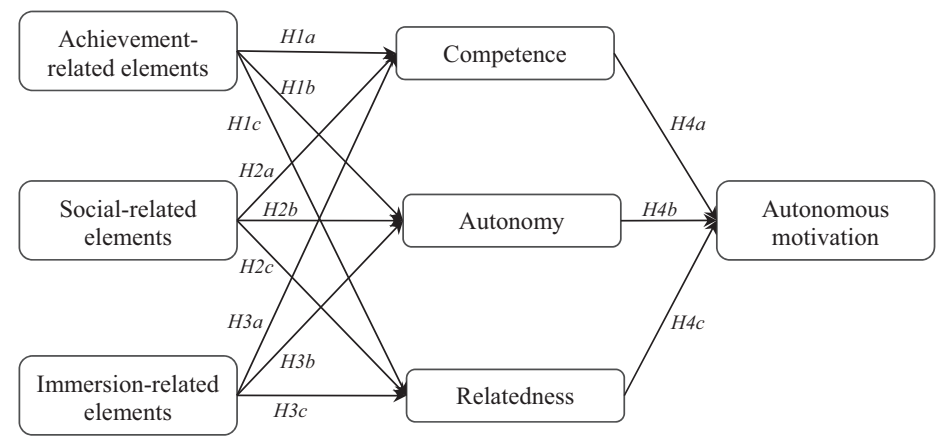

Figure 1. Proposed model 
EJMBE 29,3 users, a combination of convenience and snowball sampling was used. This sampling procedure has been used in previous studies in the context of gamification (e.g. Alahäivälä and Oinas-Kukkonen, 2016; Fitz-Walter et al., 2017; Johnson et al., 2017). An online questionnaire was sent to potential participants, including people practicing sports, sport clubs and personal trainers. The questionnaire was answered by a total of 321 individuals, of whom $156(48.6 \%)$ were users of sport apps. Only users were selected for the study. Incomplete and non-valid questionnaires were discarded, obtaining a final sample of 153 valid questionnaires.

Early and late respondents were compared to assess the presence of non-response bias (Armstrong and Overton, 1977). A comparison of means on the scores of the included constructs was conducted. No significant differences were found between both groups. Therefore, non-response bias does not seem to be an issue of concern in this study.

Table 1 shows the profile of the final sample.

\subsection{Measurement instrument}

To measure the model's constructs, seven-point scales adapted from the previous literature were used. Individuals' perceptions of game elements related to achievement, social aspects

\begin{tabular}{|c|c|c|}
\hline Category & & Percentage $(\%$, \\
\hline \multirow[t]{2}{*}{ Gender } & Men & 52.3 \\
\hline & Women & 47.7 \\
\hline \multirow[t]{4}{*}{ Age } & $<30$ years old & 39.2 \\
\hline & $30-40$ years old & 19.6 \\
\hline & $40-50$ years old & 29.4 \\
\hline & $>50$ years old & 11.8 \\
\hline \multirow[t]{6}{*}{ Weekly exercise } & $<1 \mathrm{~h}$ & 1.96 \\
\hline & $1-3 \mathrm{~h}$ & 20.92 \\
\hline & $3-6 \mathrm{~h}$ & 42.48 \\
\hline & $6-9 \mathrm{~h}$ & 20.26 \\
\hline & $9-12 \mathrm{~h}$ & 10.46 \\
\hline & $>12 \mathrm{~h}$ & 3.92 \\
\hline \multirow[t]{9}{*}{ The most-used apps } & Garmin & 20.9 \\
\hline & Strava & 17.6 \\
\hline & Polar & 12.4 \\
\hline & Runtastic & 11.1 \\
\hline & Endomondo & 9.2 \\
\hline & $\mathrm{Nike}^{+}$ & 4.6 \\
\hline & Fitbit & 4.6 \\
\hline & Runkeeper & 0.7 \\
\hline & Others & 19.0 \\
\hline \multirow[t]{6}{*}{ App experience } & $<3$ months & 5.9 \\
\hline & 3-6 months & 8.5 \\
\hline & 6-12 months & 9.2 \\
\hline & $12-18$ months & 17.0 \\
\hline & $18-24$ months & 14.4 \\
\hline & $>24$ months & 45.1 \\
\hline \multirow[t]{7}{*}{ Weekly use of the app } & $<30 \min$ & 23.5 \\
\hline & $30-60 \mathrm{~min}$ & 23.5 \\
\hline & $1-3 \mathrm{~h}$ & 23.5 \\
\hline & $3-6 \mathrm{~h}$ & 15.7 \\
\hline & $6-9 \mathrm{~h}$ & 8.5 \\
\hline & $9-12 \mathrm{~h}$ & 2.0 \\
\hline & $>12 \mathrm{~h}$ & 3.3 \\
\hline
\end{tabular}

Table 1.

Sample characteristics 
and immersion included in the apps were measured based on the scales proposed by $\mathrm{Xi}$ and Hamari (2019), which analyzed the frequency $(1=$ never, $7=$ every time) and the importance $(1=$ not at all important, $7=$ very important $)$ of the players' interactions with each of the game elements. The satisfaction of the basic psychological needs for competence and relatedness was also measured by adapting items from Xi and Hamari (2019), and the need for autonomy was measured using items from Xi and Hamari (2019) and Standage et al. (2005). The items were scored on a seven-point Likert scale $(1=$ strongly disagree; $7=$ strongly agree). Finally, autonomous motivation was conceptualized by joining intrinsic motivation and identified motivation, which were measured using scales proposed by Standage $e t$ al. (2005) on a seven-point Likert scale ( $1=$ strongly disagree, $7=$ strongly agree). Table 2 shows the measurement scales used in this study.

\subsection{Common method bias assessment}

The present study relied on data from self-reported measures in a one-time survey. Therefore, both procedural and statistical methods were used to address common method bias (Podsakoff et al., 2003). First, regarding the procedural methods, participation in the study was voluntary and the subjects were guaranteed anonymity and data confidentiality. According to Podsakoff et al. (2003), this reduces the possibility that participants will respond dishonestly or artificially. In addition, the dependent and independent variables were placed on different pages of the electronic survey, which prevented respondents from inferring cause-effect relationships among the constructs. Second, regarding the statistical procedures, a full collinearity test based on variance inflation factors (VIFs) was implemented. According to Kock (2015), this test specifies than a VIF value greater than 3.3 suggests the existence of common method bias. Our estimations showed that VIF values ranged from 1.115 to 2.577 . Therefore, there is no evidence to suggest the presence of common method bias in this study.

\section{Analyses and results}

Partial least squares (PLS) structural equation modeling with SmartPLS 3.0 software was used to test the proposed model (Ringle et al., 2015). PLS is more suitable than other methods, such as covariance-based structural equation modeling, when the conceptual model, as in our case, is complex and includes many indicators and latent variables, and constructs with formative indicators (Chin, 2010; Hair et al., 2011). In addition, it is also more appropriate when the sample size is lower than 250 (Reinartz et al., 2009).

\subsection{Measurement model analyses}

The proposed model includes both formative (interaction with achievement-related elements, interaction with social-related elements and interaction with immersion-related elements) and reflective constructs (satisfaction of the need for competence, satisfaction of the need for autonomy, satisfaction of the need for relatedness and autonomous motivation). Interaction with achievement-related game elements was conceptualized as a second-order formative construct composed of five first-order indicators: (1) badges/medals/trophies, (2) scores/ points, (3) progress bars, (4) rankings/leaderboards and (5) increasingly difficult tasks. Similarly, interaction with social-related game elements was conceptualized as a second-order formative construct composed of (1) competition, (2) social networking features and (3) cooperation. Finally, interaction with immersion-related elements was conceptualized as a second-order formative construct composed of (1) profile/virtual identity/avatar and (2) personalization. Each of these first-order constructs was measured formatively by two 


\section{EJMBE 29,3}

Constructs, items and sources

Achievement-related elements (adapted from Xi and Hamari, 2019)

A1 The frequency of interacting with badges/medals/trophies in the app

A2 The frequency of interacting with scores/points in the app

A3 The frequency of interacting with progress bars in the app

A4 The frequency of interacting with rankings/leaderboards in the app

A5 The frequency of interacting with increasingly difficult tasks in the app

A6 The importance of interacting with badges/medals/trophies in the app

A7 The importance of interacting with scores/points in the app

A8 The importance of interacting with progress bars in the app

A9 The importance of interacting with rankings/leaderboards in the app

A10 The importance of interacting with increasingly difficult tasks in the app

Social-related elements (adapted from Xi and Hamari, 2019)

S1 The frequency of interacting with competition in the app

S2 The frequency of interacting with social networking features in the app

S3 The frequency of interacting with cooperation in the app

S4 The importance of interacting with competition in the app

S5 The importance of interacting with social networking features in the app

S6 The importance of interacting with cooperation in the app

Immersion-related elements (adapted from Xi and Hamari, 2019)

I1 The frequency of interacting with profile/virtual identity/avatar in the app

I2 The frequency of interacting with personalization in the app

I3 The importance of interacting with profile/virtual identity/avatar in the app

I4 The importance of interacting with personalization in the app

Competence (adapted from Xi and Hamari, 2019)

C1 I think that I am pretty good when I use the app

C2 I am satisfied with my performance when I use the app

C3 I feel like an expert in the app

C4 I feel like a competent person when I use the app

Autonomy (adapted from Xi and Hamari, 2019; Standage et al., 2005)

A1 In this app I have different options

A2 I feel free to use this app

A3 I feel free to decide what activities to do in the app

A4 When I use the app, it is because I want to use it

Relatedness (adapted from Xi and Hamari, 2019)

R1 When I use the app, I feel like other people care what I do

R2 When I use the app, I feel supported by others

R3 When I use the app, I feel that I am a valuable person to others

R4 When I use the app, I feel that I am understood

Autonomous motivation

Intrinsic motivation (adapted from Standage et al., 2005)

IN1 I use the app because it is fun

IN2 I use the app because I like it

IN3 I use the app because it is interesting

Identified motivation (adapted from Standage et al., 2005)

ID1 I use the app because I want to do exercise

Table 2.

ID2

ID3
I use the app because it is important for me to do exercise

I use the app because I want to improve my physical condition 
indicators: frequency of interaction with the game element and the importance of the Gamification in interaction with the game element.

First, the external validity of the formative measurement model was assessed by evaluating indicators' weights and loadings (see Table 3). The indicators of formative constructs should have statistically significant weights. However, according to Hair et al. (2017), indicators with non-significant weights but high loadings (i.e. above 0.50) have high absolute influence on the constructs, and should therefore be retained in the model. As can be seen in Table 3, while some indicators have low and non-significant weights, all have loadings above 0.50 and are significant, which indicates acceptable external validity (Hair et al., 2017). In addition, collinearity was assessed based on the VIF values. According to Hair et al. (2011), a VIF value of 5 and higher indicates a potential collinearity problem. As can be seen in Table 3, the VIFs range from 1.107 to 3.539, all lower than 5, which suggests that multicollinearity is not a threat in this study.

Second, the reliability and validity of the reflective measurement model were assessed. The reliability was evaluated based on the criterion that factor loadings should be higher than 0.7 (Churchill, 1979). As Table 4 shows, all standardized factor loadings were above 0.7 and statistically significant at 0.01 (Carmines and Zeller, 1979), which indicatesthat individual item reliability was adequate. Moreover, all the constructs were internally consistent, as their composite reliabilities (CR) were greater than 0.7 (Nunnally and Bernstein, 1994). The constructs also met the convergent validity criteria, as the average variance extracted (AVE) values were above 0.5 (Fornell and Larcker, 1981). Finally, as Table 5 shows, discriminant validity was also demonstrated. In all cases, the square root of the AVE of any two constructs was greater than the inter-construct correlations (Fornell and Larcker, 1981).

\subsection{Structural model analyses}

The analysis of the proposed hypotheses was based on the examination of standardized paths, which were estimated using a bootstrapping procedure with 5,000 subsamples (Chin, 1998). The model accounted for $22.0 \%$ of the variation of the satisfaction of the need for competence, $20.8 \%$ of the variation of the satisfaction of the need for autonomy and $67.7 \%$ of variation of the satisfaction of the need for relatedness. Finally, it accounted for $20.8 \%$ of the variation in individuals' autonomous motivation. The predictive relevance of the model was assessed through the Stone-Geisser test. In particular, the results showed that the $\underline{Q}^{2}$ values for the dependent variables were positive.

The results indicated that interaction with achievement-related game elements in the gamified app promoted the satisfaction of the needs for competence $(\beta=0.307 ; t=3.00)$,

\begin{tabular}{llcrrrrr}
\hline Variables & Items & Loading & $t$-value & Weight & $t$-value & VIF \\
\hline Achievement-related & Badges/medals/trophies & 0.870 & 19.25 & 0.350 & 2.77 & 2.146 & \\
elements & Scores/points & 0.648 & 9.78 & 0.095 & 1.05 & 1.669 \\
& Progress bars & 0.578 & 7.31 & 0.129 & 1.14 & 1.707 \\
& Rankings/leaderboards & 0.940 & 25.50 & 0.592 & 4.18 & 2.313 \\
& Increasingly difficult tasks & 0.596 & 7.17 & 0.005 & 0.04 & 1.739 \\
Social-related elements & Competition & 0.833 & 13.43 & 0.468 & 4.14 & 1.634 & \\
& Social networking features & 0.883 & 16.85 & 0.496 & 3.80 & 2.875 \\
Immersion-related elements & Cooperation & 0.886 & 21.95 & 0.914 & 1.58 & 3.559 & \\
& Profile/virtual identity/ & 0.931 & 8.26 & 0.814 & 4.93 & 1.105 & Table 3. \\
& avatar & & & & & & Formative \\
& Personalization & 0.633 & 4.14 & 0.383 & 2.07 & 1.105 & measurement model \\
& & & & & &
\end{tabular}


EJMBE 29,3

\section{4}

Table 4.

Reflective measurement model results autonomy $(\beta=0.331 ; t=3.26)$ and relatedness $(\beta=0.263 ; t=3.23)$, which support H1a, H1b and H1c, respectively. Similarly, interaction with social-related game elements was associated with the satisfaction of the need for relatedness $(\beta=0.721 ; t=6.50)$, supporting H2c. However, we found no significant impact of social-related elements on the satisfaction of the needs for competence $(\beta=-0.141 ; t=1.14)$ and autonomy $(\beta=-0.140$; $t=1.30$ ), thus rejecting $\mathrm{H} 2 \mathrm{a}$ and $\mathrm{H} 2 \mathrm{~b}$. Similarly, the results showed that interaction with immersion-related game elements favored the satisfaction of the needs for competence $(\beta=0.344 ; t=2.64)$ and autonomy $(\beta=0.314 ; t=3.03)$, which support H3a and H3b, respectively. However, contrary to the prediction, we found no significant impact of immersion-related game elements on the satisfaction of the need for relatedness $(\beta=-0.149$; $t=1.53$ ), rejecting $\mathrm{H} 3 \mathrm{c}$.

The results also demonstrated that satisfaction of the needs for autonomy $(\beta=0.377$; $t=3.92)$ and for relatedness $(\beta=0.162 ; t=1.77)$ when using the gamified app was positively associated with individuals' autonomous motivation. Thus, $\mathrm{H} 4 \mathrm{~b}$ and $\mathrm{H} 4 \mathrm{c}$ are accepted. On the contrary, satisfaction of the need for competence did not have a significant effect on autonomous motivation $(\beta=0.002 ; t=0.02)$, which rejects H4a.

This study included as control variables weekly exercise, weekly use of the app and the length of time that users have been using the app (app experience). Furthermore, gender and

\begin{tabular}{llcccc}
\hline Variables & Items & Factor loading & CR & AVE & $Q^{2}$ \\
\hline Competence & C1 & 0.870 & 0.916 & 0.732 & 0.146 \\
& C2 & 0.763 & & & \\
C3 & 0.897 & & & \\
Autonomy & C4 & 0.888 & 0.909 & 0.714 & 0.140 \\
& A1 & 0.813 & & & \\
Relatedness & A2 & 0.867 & & & \\
& A3 & 0.896 & & 0.927 & 0.583 \\
& A4 & 0.802 & & & \\
Autonomous motivation & R2 & 0.941 & 0.981 & & \\
& R3 & 0.983 & & & \\
& R4 & 0.975 & & & \\
& IN1 & 0.953 & 0.693 & \\
& IN2 & 0.783 & 0.931 & & \\
& IN3 & 0.877 & & & \\
& ID1 & 0.825 & & &
\end{tabular}

Note(s): CR: composite reliability; AVE: average variance extracted

\begin{tabular}{lccccccc}
\hline & 1 & 2 & 3 & 4 & 5 & 6 & 7 \\
\hline 1. Achievement-related elements & N.A. & & & & & & \\
2. Social-related elements & 0.675 & N.A. & & & & & \\
3. Immersion-related elements & 0.538 & 0.696 & N.A. & & & & \\
4. Competence & 0.397 & 0.306 & 0.411 & 0.856 & & & \\
5. Autonomy & 0.405 & 0.302 & 0.395 & 0.499 & 0.845 & & \\
6. Relatedness & 0.670 & 0.796 & 0.495 & 0.341 & 0.268 & 0.963 & \\
7. Autonomous motivation & 0.371 & 0.317 & 0.364 & 0.194 & 0.372 & 0.222 & 0.833
\end{tabular}

Table 5.

Discriminant validity analysis
Note(s): Diagonal values with the AVE square roots. Elements which are not in the diagonal are construct correlations. N.A.: not applied 
age were considered. The results showed that individuals who have been users of the app for Gamification in longer are less autonomously motivated than those who became users more recently.

Table 6 shows the summary of the results of the structural model. sport apps

\section{Discussion}

Due to its ability to motivate individuals, gamification has in recent years triggered great interest among academics and professionals from different sectors. One context where gamification has received special attention is in sport apps for mobile devices. Game elements (medals, rankings, progress bars, avatars, competition, etc.) are included in a variety of gamified sport apps to motivate individuals to perceive exercise as an interesting and fun activity.

Drawing on self-determination theory, this research proposes a model to understand how different categories of game elements in sport apps (achievement-oriented, social-oriented and immersion-oriented) facilitate the satisfaction of the basic psychological needs of individuals and their impact on autonomous motivation.

Specifically, based on the empirical results obtained, it can be concluded that interacting with achievement-related game elements (e.g. badges, results, progress bars, rankings and difficulty levels) while using gamified sport apps facilitates the satisfaction of the three psychological needs of competence, autonomy and relatedness. For instance, receiving medals/badges can create a feeling of competence, because these lead users to perceive they have the required skills to successfully achieve their goals. On the other hand, elements such as progress bars and difficulty levels can create a feeling of autonomy, as individuals tend to feel more freedom when managing the app. Finally, elements such as rankings evoke a greater perception of relatedness with others, because players thereby can compare their performance with that of other users. These results are in line with previous studies in educational contexts and online brand communities (e.g. van Roy and Zaman, 2019; Xi and Hamari, 2019), where it has also been found that achievement-related game elements help individuals to feel more competent and autonomous and to interact with others.

Regarding the interaction with social-related game elements in apps (e.g. competition, social networks and cooperation), results have shown that these are predictors only of the satisfaction of the need for relatedness. We found they had no significant effect on the satisfaction of the needs for competence and autonomy. This result is in line with the study

\begin{tabular}{lccr}
\hline Hypotheses & $\beta$ & $t$-value & $p$-value \\
\hline H1a: Achievement-related elements $\rightarrow$ Competence & 0.307 & 3.00 & 0.001 \\
H1b: Achievement-related elements $\rightarrow$ Autonomy & 0.331 & 3.26 & 0.001 \\
H1c: Achievement-related elements $\rightarrow$ Relatedness & 0.263 & 3.23 & 0.001 \\
H2a: Social-related elements $\rightarrow$ Competence & -0.141 & 1.14 & 0.127 \\
H2b: Social-related elements $\rightarrow$ Autonomy & -0.140 & 1.30 & 0.097 \\
H2c: Social-related elements $\rightarrow$ Relatedness & 0.721 & 6.50 & 0.000 \\
H3a: Immersion-related elements $\rightarrow$ Competence & 0.344 & 2.64 & 0.004 \\
H3b: Immersion-related elements $\rightarrow$ Autonomy & 0.314 & 3.03 & 0.001 \\
H3c: Immersion-related elements $\rightarrow$ Relatedness & -0.149 & 1.53 & 0.062 \\
H4a: Competence $\rightarrow$ Autonomous motivation & 0.002 & 0.02 & 0.493 \\
H4b: Autonomy $\rightarrow$ Autonomous motivation & 0.377 & 3.92 & 0.000 \\
H4c: Relatedness $\rightarrow$ Autonomous motivation & 0.162 & 1.77 & 0.038 \\
Control variables & & & 0.008 \\
App experience & -0.168 & 2.42 & 0.210 \\
Weekly use of the app & 0.072 & 0.80 & 0.456 \\
Weekly exercise & -0.010 & 0.11 & 0.058 \\
Gender & 0.128 & 1.57 & 0.096
\end{tabular}

Table 6. Structural model results 
EJMBE 29,3 carried out by Sailer et al. (2017), who also found that social-related game elements had a significant effect on the satisfaction of the need for relatedness. Previous research has shown that competition facilitates the sense of belonging to a group (van Roy and Zaman, 2019), cooperation encourages individuals to work together to achieve a common goal (Sailer $e t$ al., 2017) and social networking features allow people to communicate with others. These socialrelated game elements are directly linked to relationships with other individuals. Hence, this might explain why they have an effect only on the satisfaction of the need for relatedness, and not on the other two needs.

The results of the present study also showed that individuals' interaction in apps with immersion-related elements (e.g. avatars and customization) facilitated the satisfaction of the basic needs for competence and autonomy. These results have corroborated others obtained in previous studies, which also found that sense of autonomy is enhanced by the individual's ability to create characters and avatars and to customize or personalize different aspects of the app (Kim et al., 2015; Peng et al., 2012), as they feel freer to make it their own. This category of game elements also facilitates competence, because users feel they control the app and are able to make these kinds of changes and customization. On the other hand, the results did not demonstrate that these game elements had an effect on the satisfaction of the need for relatedness. This may be because when users create their profile and customize their training, they set individual objectives that do not necessarily coincide with those of the community or encourage relationships with other players.

In line with self-determination theory, the results of the present study have shown that there is a positive relationship between the satisfaction of the basic psychological needs for autonomy and relatedness on individuals' autonomous motivation. Therefore, people will be more motivated to use the app and exercise when they feel a sense of freedom and can decide which activities and training they want to undertake while using the app. Furthermore, the support and assessment of other users of the app will be crucial for motivation. However, no significant relationship was found between the satisfaction of the need for competence and autonomous motivation. Hence, that individuals do not consider themselves very competent while using apps is not an impediment for them to be motivated to use them.

Lastly, regarding the control variables, the results showed that the length of time that individuals have been using the app negatively affects autonomous motivation to continue using it, because they perceive it as less fun and interesting than do users who have been using it for a shorter period of time. This could be explained by the "novelty effect," that is, that the effects derived from gamification reduce in the long term as players' initial curiosity about the game elements, which previously seemed original and motivating, diminishes (Hamari et al., 2014; Hamari, 2017; Koivisto and Hamari, 2014).

The present study provides a number of theoretical contributions. First, previous studies have highlighted that gamification studies based on theoretical frameworks that seek to understand and explain the effects of gamification are still scarce (Hamari et al., 2014; Seaborn and Fels, 2015; Johnson et al., 2016; Matallaoui et al., 2017; Sailer et al., 2017). Therefore, the present study contributes to the literature by using a human motivation theory, selfdetermination theory, as a basis to analyze users' affective and attitudinal responses. Second, prior research has noticed that there is a lack of empirical evidence of the effectiveness of gamification in sports and health contexts (Edwards et al., 2016; Johnson et al., 2016; Sardi et al., 2017; Koivisto and Hamari, 2019b). Hence, this research extends the existing gamification literature by offering empirical evidence about its effectiveness in the context of sport apps for mobile devices. Third, recent literature reviews have revealed the lack of knowledge about the effect of different game elements, as most studies are focused on analyzing gamification as a uniform concept (Johnson et al., 2016; Sailer et al., 2017). Therefore, this study contributes to the literature by analyzing the effect of three different categories of game element (achievement related, social related and immersion related) on 
individuals' basic psychological needs. Fourth, prior studies have focused on analyzing individuals' behavioral outcomes, and not taken psychological variables, such as motivation, into account (Seaborn and Fels, 2015). Thus, this research extends gamification literature by focusing on users' gamification and its antecedents. Finally, another limitation of previous studies is their lack of validated scales (Matallaoui et al., 2017). The present research, in contrast, offers an empirical study based on scales previously validated in the literature to measure individuals' perceptions of the variables of the proposed model.

The present study also provides a number of practical contributions for gamified app developers. The purpose of gamification is to integrate game design elements into non-game contexts to motivate people to behave in certain ways. Hence, understanding the determinants of motivation is important to successfully design and implement gamified apps. Based on the results obtained in this study, it can be concluded that individuals' autonomous motivation to use a gamified sport app is determined by the ability of the app to meet their basic psychological needs for autonomy and relatedness. To achieve a perception of autonomy, apps must include achievement-related game elements and immersion-related elements. These elements give app users a sense of freedom in decision-making, which ultimately is a major motivation to use the app. In this regard, it is recommendable that sport apps are designed in a way that allows users to see and save their results. For instance, apps can provide users with different options on trainings and challenges, and based on their performances, they can reward them with different medals. In order not to lose initial interest, these challenges should be designed using increasingly difficulty levels, so that users feel that their achievements are evolving. Likewise, app developers should include immersive elements within the app design, such as letting users create an avatar by choosing different aspects (e.g. shape of face, color and length of hair) so that the avatar physically resembles the user, and letting users customize the app (e.g. choosing an image for the wallpaper, designing bespoke trainings using exercises included in the app). On the other hand, as to the satisfaction of the need for relatedness, achievement-related game elements, such as rankings, also evoke a perception of relatedness. However, the game elements which have the greatest effect are social related. These types of game elements encourage app users to interact with others and allow them to feel part of the app community, which ultimately translates into a major motivation to use the app. To do so, first, it is recommendable to create an app community in which users can interact with other users by sharing their trainings, their walking and running tours or their recipes to eat healthier, among others. Once the community is created, sport apps should give users the opportunity to send invitations to their Facebook friends to join the app, as well as to share their achievements on Twitter, Facebook or the app community, so that their friends can see them, recognize their efforts with Likes and encourage them through motivating comments. To promote this sense of relatedness, users should also be able to compete and cooperate not only with their friends, but also with other members of the app community. To do so, app developers should consider the possibility of designing different challenges that require cooperation (e.g. a challenge in which users are required to invite app friends to join a team to complete a marathon considering the steps of all team members in one day) or foster competition (e.g. inviting friends to a competition on walking the most steps in one week). Finally, despite the fact that the present study did not confirm that satisfaction of the need for competence has a direct impact on autonomous motivation, if app developers want users to feel competent when using it, they should allow them to interact with achievement and immersion-related game elements. In short, the results of the present study allow us to identify which game elements of the app are associated with the satisfaction of the three types of need. Therefore, app developers and other entities can, in accordance with their strategies, focus on those that most interest them.

Finally, the present study has several limitations which offer avenues for future lines of research. First, the use of convenience and snowball sampling is a limitation of this study. 
EJMBE 29,3

\section{8}

Future research should use probabilistic sampling methods to enhance the generalization of results. Likewise, increasing the sample size would allow the results to be generalized. For instance, future studies could try to contact with sport app developers to have access to all registered users. Second, only psychological variables have been analyzed in this study; other behavioral variables have not been considered. In this sense, it would be interesting for future research to adopt a complete and sequential influence of gamification on individuals' responses. Third, this study used cross-sectional data. Therefore, it has not been possible to analyze the effects of gamification on individuals in the long term. Taking this into account, it would be interesting to undertake longitudinal studies that will allow an analysis of the evolution of the effects of gamification over time and establish, thus, whether the initial motivation that arises as a consequence of the novelty of the apps is maintained or diminishes.

\section{References}

Alahäivälä, T. and Oinas-Kukkonen, H. (2016), "Understanding persuasion contexts in health gamification: a systematic analysis of gamified health behavior change support systems literature", International Journal of Medical Informatics, Vol. 96, pp. 62-70.

Armstrong, J.S. and Overton, T.S. (1977), "Estimating nonresponse bias in mail surveys", Journal of Marketing Research, Vol. 14 No. 3, pp. 396-402.

Baptista, G. and Oliveira, T. (2017), "Why so serious? Gamification impact in the acceptance of mobile banking services", Internet Research, Vol. 27 No. 1, pp. 118-139.

Baumeister, R. and Leary, M. (1995), "The need to belong: desire for interpersonal attachments as a fundamental human motivation”, Psychology Bulletin, Vol. 117 No. 3, pp. 497-529.

Bormann, D. and Greitemeyer, T. (2015), "Immersed in virtual worlds and minds: effects of in-game storytelling on immersion, need satisfaction, and affective theory of mind", Social Psychological and Personality Science, Vol. 6 No. 6, pp. 646-652.

Carmines, E. and Zeller, R. (1979), "Reliability and validity assessment", in J., Sullivan and R., Niemi (Eds), Sage University Paper Series on Quantitative Applications in the Social Sciences, Sage Publications, Beverly Hills and London.

Chen, Y. and Pu, P. (2014), "Healthy together: exploring social incentives for mobile fitness applications", in Proceedings of Chinese CHI'14, Toronto, pp. 25-34.

Chin, W.W. (1998), "The partial least squares approach for structural equation modelling", in Marcoulides, G.A. (Ed.), Modern Methods for Business Research, Lawrence Erlbaum Associates, London, pp. 295-336.

Chin, W.W. (2010), "How to write up and report PLS analyses", in Handbook of Partial Least Squares, Springer, Berlin, Heidelberg, pp. 655-690.

Churchill, G.A. (1979), "A paradigm for developing better measures of marketing constructs", Journal of Marketing Research, Vol. 16, pp. 64-73.

Connolly, T., Boyle, E., MacArthur, E., Hainey, T. and Boyle, J. (2012), "A systematic literature review of empirical evidence on computer games and serious games", Computers \& Education, Vol. 59, pp. 661-686.

de Charms, R. (1968), Personal Causation, Academic, New York, NY.

de Cooman, R., Stynen, D., Van den Broeck, A., Sels, L. and de White, H. (2013), "How job characteristics relate to need satisfaction and autonomous motivation: implications for work effort", Journal of Applied Social Psychology, Vol. 43 No. 6, pp. 1342-1352.

Deci, E. (1975), Intrinsic Motivation, Plenum Press, New York, NY.

Deci, E. and Ryan, R. (2000), "The 'what' and 'why' of goal pursuits: human needs and the selfdetermination of behavior", Psychological Inquiry, Vol. 11, pp. 227-268. 
Deci, E.L. and Ryan, R.M. (2008), "Facilitating optimal motivation and psychological well-being across life's domains", Canadian Psychology, Vol. 49 No. 1, pp. 14-23.

Deci, E. and Ryan, R. (2015), Self-Determination Theory, 2nd ed., International Encyclopedia of the Social \& Behavioral Sciences, pp. 486-491, available at: https://www.sciencedirect.com/ referencework/9780080970875/international-encyclopedia-of-the-social-and-behavioral-sciences.

Deci, E., Ryan, R. and Williams, G. (1996), "Need satisfaction and the self-regulation of learning", Learning and Individual Differences, Vol. 8 No. 3, pp. 165-183.

Deterding, S., Dixon, D., Khaled, R. and Nacke, L. (2011), "From game design elements to gamefulness: defining "gamification", in Proceedings of the 15th International Academic MindTrek Conference: Envisioning Future Media Environments, ACM, pp. 9-15.

Ding, L., Er, E. and Orey, M. (2018), “An exploratory study of student engagement in gamified online discussions”, Computers \& Education, Vol. 120, pp. 213-226.

Edmunds, J., Ntoumanis, N. and Duda, J.L. (2007), “Adherence and well-being in overweight and obese patients referred to an exercise on prescription scheme: a self-determination theory perspective", Psychology of Sport and Exercise, Vol. 8 No. 5, pp. $722-740$.

Edwards, E.A., Lumsden, J., Rivas, C., Steed, L., Edwards, L.A., Thiyagarajan, A., Sohanpal, R., Caton, H., Griffiths, C.J., Munafô, M.R., Taylor, S. and Walton, R.T. (2016), "Gamification for health promotion: systematic review of behaviour change techniques in smartphone apps", $B M J$ Open, Vol. 6 No. 10, e012447.

Fitz-Walter, Z., Johnson, D., Wyeth, P., Tjondronegoro, D. and Scott-Parker, B. (2017), "Driven to drive? Investigating the effect of gamification on learner driver behavior, perceived motivation and user experience", Computers in Human Behavior, Vol. 71, pp. 586-595.

Fornell, C. and Larcker, D.F. (1981), "Evaluating structural equation models with unobservable variables and measurement error", Journal of Marketing Research, Vol. 18, pp. 39-50.

Hair, J.F., Ringle, C.M. and Sarstedt, M. (2011), "PLS-SEM: indeed a silver bullet", Journal of Marketing Theory and Practice, Vol. 19 No. 2, pp. 139-152.

Hair, J., Hollingsworth, C.L., Randolph, A.B. and Chong, A.Y.L. (2017), "An updated and expanded assessment of PLS-SEM in information systems research", Industrial Management \& Data Systems, Vol. 117 No. 3, pp. 442-458.

Hamari, J. (2017), "Do badges increase user activity? A field experiment on the effects of gamification", Computers in Human Behavior, Vol. 71, pp. 469-478.

Hamari, J. and Parvinen, P. (2018), "Introduction to gamification minitrack", in Proceedings of the 51st Hawaii International Conference on System Sciences, pp. 1106-1107.

Hamari, J., Koivisto, J. and Sarsa, H. (2014), "Does gamification work?-a literature review of empirical studies on gamification", in HICSS, Vol. 14, pp. 3025-3034.

Hassan, L., Dias, A. and Hamari, J. (2019), "How motivational feedback increases user's benefits and continued use: a study on gamification, quantified-self and social networking”, International Journal of Information Management, Vol. 46, pp. 151-162.

Huang, H., Wong, M., Yang, Y., Chiu, H. and Teng, C. (2017), "Impact of playing exergames on mood states: a randomized control trail", Cyberpsychology, Behavior, and Social Networking, Vol. 20 No. 4, pp. 246-250.

Johnson, D., Deterding, S., Kuhn, K.A., Staneva, A., Stoyanov, S. and Hides, L. (2016), "Gamification for health and wellbeing: a systematic review of the literature", Internet Interventions, Vol. 6, pp. 89-106.

Johnson, D., Horton, E., Mulcahy, R. and Foth, M. (2017), "Gamification and serious games within the domain of domestic energy consumption: a systematic review”, Renewable and Sustainable Energy Reviews, Vol. 73, pp. 249-264.

Kim, K., Schmierbach, M.G., Chung, M.Y., Fraustino, J.D., Dardis, F. and Ahern, L. (2015), "Is it a sense of autonomy, control, or attachment? Exploring the effects of in-game customisation on game enjoyment", Computers in Human Behavior, Vol. 48, pp. 695-705. 
EJMBE 29,3

Kock, N. (2015), "Common method bias in PLS-SEM: a full collinearity assessment approach", International Journal of e-Collaboration (IJeC), Vol. 11 No. 4, pp. 1-10.

Koivisto, J. and Hamari, J. (2014), "Demographic differences in perceived benefits from gamification", Computers in Human Behavior, Vol. 35, pp. 179-188.

Koivisto, J. and Hamari, J. (2019a), "The rise of motivational information systems: a review of gamification research", International Journal of Information Management, Vol. 45, pp. 191-210.

Koivisto, J. and Hamari, J. (2019b), "Gamification of physical activity: a systematic literature review of comparison studies", in GamiFIN, pp. 106-117.

Lucassen, G. and Jansen, S. (2014), "Gamification in consumer marketing - future or fallacy?", Procedia-Social and Behavioral Sciences, Vol. 148, pp. 194-202.

Matallaoui, A., Koivisto, J., Hamari, J. and Zarnekow, R. (2017), "How effective is 'exergamification'? A systematic review on the effectiveness of gamification features in exergames", in Proceedings of the 50th Hawaii International Conference on System Sciences.

Mekler, E.D., Brühlmann, F., Tuch, A.N. and Opwis, K. (2017), "Towards understanding the effects of individual gamification elements on intrinsic motivation and performance", Computers in Human Behavior, Vol. 71, pp. 525-534.

Ng, J., Ntoumanis, N., Thogersen-Ntoumani, C., Deci, E., Ryan, R., Duda, J. and Williams, G. (2012), "Self-determination theory applied to health contexts: a meta-analysis", Perspectives on Psychological Science, Vol. 7 No. 4, pp. 325-340.

Nunnally, J.C. and Bernstein, I.H. (1994), Psychometric Theory, 3rd ed., McGraw-Hill, New York, NY.

Peng, W., Lin, J., Pfeiffer, K. and Winn, B. (2012), "Need satisfaction supportive game features as motivational determinants: an experimental study of a selfdetermination theory guided exergame”, Media Psychology, Vol. 15, pp. 175-196.

Podsakoff, P.M., MacKenzie, S.B., Lee, J.Y. and Podsakoff, N.P. (2003), "Common method biases in behavioral research: a critical review of the literature and recommended remedies", Journal of Applied Psychology, Vol. 88 No. 5, pp. 879-903.

Reinartz, W., Haenlein, M. and Henseler, J. (2009), "An empirical comparison of the efficacy of covariance-based and variance-based SEM", International Journal of Research in Marketing,Vol. 26, pp. 332-344.

Ringle, C., Wende, S. and Becker, J. (2015), SmartPLS 3, SmartPLS, Bönningstedt.

Robson, K., Plangger, K., Kietzmann, J., McCarthy, I. and Pitt, L. (2015), "Is it all a game? Understanding the principles of gamification", Business Horizons, Vol. 58 No. 4, pp. 411-420.

Ryan, R.M. and Deci, E.L. (2000), "Self-determination theory and the facilitation of intrinsic motivation, social development, and well-being", American Psychologist, Vol. 55, pp. 68-78.

Ryan, R., Rigby, C. and Przybylski, A. (2006), "The motivational pull of video games: a selfdetermination theory approach", Motivation and Emotion, Vol. 30 No. 4, pp. 344-360.

Sailer, M., Hense, J., Mandl, J. and Klevers, M. (2013), "Psychological perspectives on motivation through gamification”, Interaction Design and Architecture Journal, Vol. 19, pp. 28-37.

Sailer, M., Hense, J., Mayr, S. and Mandl, H. (2017), "How gamification motivates: an experimental study of the effects of specific game design elements on psychological need satisfaction", Computers in Human Behavior, Vol. 69, pp. 371-380.

Sardi, L., Idri, A. and Fernández-Alemán, J.L. (2017), “A systematic review of gamification in e-Health”, Journal of Biomedical Informatics, Vol. 71, pp. 31-48.

Seaborn, K. and Fels, D. (2015), "Gamification in theory and action: a survey", International Journal of Human-Computer Studies, Vol. 74, pp. 14-31.

Sigala, M. (2015), "The application and impact of gamification funware on trip planning and experiences: the case of TripAdvisor's funware”, Electronic Markets, Vol. 25 No. 3, pp. 189-209. 
Standage, M., Duda, J.L. and Ntoumanis, N. (2005), "A test of self-determination theory in school Gamification in physical education”, British Journal of Educational Psychology, Vol. 75 No. 3, pp. 411-433.

van Roy, R. and Zaman, B. (2019), "Unravelling the ambivalent motivational power of gamification: a sport apps basic psychological needs perspective", International Journal of Human-Computer Studies, Vol. 127, pp. 38-50.

White, R. (1959), "Motivation reconsidered: the concept of competence", Psychology Review, Vol. 66 No. 5, pp. 297-333.

Xi, N. and Hamari, J. (2019), "Does gamification satisfy needs? A study on the relationship between gamification features and intrinsic need satisfaction", International Journal of Information Management, Vol. 46, pp. 210-221.

\section{Corresponding author}

Isabel Buil can be contacted at: ibuil@unizar.es

For instructions on how to order reprints of this article, please visit our website:

www.emeraldgrouppublishing.com/licensing/reprints.htm

Or contact us for further details: permissions@emeraldinsight.com 